\title{
WORK-RELATED STRESS, PERSONAL RESOURCES AND MENTAL HEALTH IN HIGH RISK PROFESSIONS: CROSS-SECTIONAL SURVEY
}

\author{
Martina Chylova $^{1}$, Jana Nezkusilova ${ }^{2}$, Livia Pestova ${ }^{1}$, \& Monika Seilerova ${ }^{3}$ \\ ${ }^{1} 1^{\text {st }}$ Department of Psychiatry, Faculty of Medicine, P. J. Safarik University, Kosice (Slovakia) \\ ${ }^{2}$ Department of Psychology, Faculty of Arts, P. J. Safarik University, Kosice (Slovakia) \\ ${ }^{3}$ Department of Labour Law and Social Security Law, Faculty of Law, P. J. Safarik University, \\ Kosice (Slovakia)
}

\begin{abstract}
The importance of work-related stress and its consequences for mental health is underlined by the increasing prevalence of absence from work due to stress-related illnesses. Psychosocial stress, depression, burnout and anxiety are the third most common causes of absenteeism and fluctuation of staff in the European workplaces. The aim of this study was to explore how work-related stress and personal resources associate with perceived anxiety and depression in high-risk professions. The study sample consisted of 276 police officers, prison guards, customs officers and physicians $(72.1 \%$ men, average age 36.6 years) who filled out questionnaires focused on sociodemographic variables (age, gender, working time), work-related stress (occupational roles, personal resources OSI-R), anxiety (STAI X-1) and depression (SDS). Hierarchical multiple regression analysis was performed to analyze the data. A model consisting of gender, occupational roles and personal resources explained $39.5 \%$ of the variance in anxiety, and $48.7 \%$ of the variance in depression in the total sample. Gender $(\beta=.22, p \leq .001)$, recreation $(\beta=-.26, p \leq .001)$, social support $(\beta=-.17, \mathrm{p} \leq .01)$ and rational/cognitive coping $(\beta=-.17, \mathrm{p} \leq .01)$ were significant predictors of anxiety. Gender $(\beta=.26, p \leq .001)$, insufficiency $(\beta=.11, p \leq .05)$, ambiguity $(\beta=.13$, $\mathrm{p} \leq .05)$, recreation $(\beta=-.19, \mathrm{p} \leq .001)$, social support $(\beta=-.19, \mathrm{p} \leq .001)$ and rational $/ \operatorname{cog}$ nitive $\operatorname{coping}(\beta=-.24$, $\mathrm{p} \leq .001)$ were significant predictors of depression. This model supports the role of personal resources in reducing of perceived anxiety and depression in the studied sample. Higher levels of recreation, social support and rational/cognitive coping strategies in the work of high-risk employees are important in diminishing perceived anxiety and depression, and potentially protect against work-related stress.
\end{abstract}

Keywords: Work-related stress, anxiety, depression, personal resources, mental health.

\section{Introduction}

Work has been identified as a significant predictor of mental health problems. Mental disorders are the leading causes of disability in Slovakia. In some high-income countries, nearly $40 \%$ of disabilities are caused by the occurrence of mental disorders (Baumann et al., 2010). The importance of work-related stress and its consequences for mental health is underlined by the increasing prevalence of absence from work due to stress-related illnesses. Research in the field of work-related stress is still insufficient in Slovakia, although occupational physicians and employers estimate an increasing trend in disability due to mental disorders (NCZI, 2018).

Psychosocial work factors may affect negatively mental well-being of employees. Work-related stress may trigger developing of anxious disorders or depression (Madsen et al., 2017). Anxiety and depression have become the most common mental disorders nowadays, and are manifested in varying intensity. The anxious employees consider day-to-day events as threatening, although they are not necessarily serious. This can lead to avoidance of tasks instead of use of effective skills to solve the tasks. Depressed employees may express emotional, motivational, physiological and cognitive symptoms. Some of them experience suicidal thoughts or actions (Bennett, 2011).

Responders included in this study worked in the emergency services in the government and health care. They have dynamic work environment with various psychosocial work stressors. The stressors responsible for poor mental health in customs officers, prison guards or policemen are long hours at work and overtime, conflicting demands, poor social support, badly-designed organizational structure, employee reward system, working with dangerous clients. Furthermore, many physicians are notoriously reluctant to seek help. There is an increased level of psychological morbidity among high risk employees, such as anxiety, depression, or substance abuse (Schneider, Weigl, 2018). 


\section{Design and objectives}

The aim of the cross-sectional survey was to find out how work-related stress and personal resources predict perceived anxiety and depression in high risk professions. It was expected that variables of work-related stress predict higher rates of anxiety and depression, while higher levels of personal resources predict less anxiety and depression in the study sample. Dependent variables were anxiety, depression, while independent variables were gender, occupational roles and personal resources.

\section{Methods}

\subsection{Sample}

The study sample consisted of 276 responders. They were predominantly men $(72.1 \%)$ working in risk positions, such as policemen, prison guards, customs officers and physicians. 51.4\% of them worked in shifts, $75.7 \%$ worked at night, $62.3 \%$ worked overtime, and $48.2 \%$ worked in the emergency services. Their average age was 36.6 years, with range $18-77$ years.

\subsection{Measures}

Responders filled out questionnaires focused on sociodemographic variables (age, gender), and working time. Work-related stress was measured by the Occupational Stress Inventory Revised (OSI-R), particularly by the questionnaires Occupational Role (ORQ, 60 items) and Personal Resources (PRQ, 40 items). Anxiety was detected by the State Trait Anxiety Inventory (STAI X-1, 20 items), and depression by the Zung Self-Rating Depression Scale (SDS, 20 items).

Hierarchical multiple regression analysis, the stepwise method, was performed to determine predictors of anxiety and depression in this study.

\section{Results}

Two models consisted of gender, occupational roles ORQ (overload, insufficiency, ambiguity, boundary, responsibility, physical environment), and personal resources PRQ (recreation, self-care, social support, rational/cognitive coping). Significant predictors of anxiety were female gender $(\beta=.22, \mathrm{p} \leq .001)$, lower levels of recreation $(\beta=-.26, \mathrm{p} \leq .001)$, social support $(\beta=-.17, \mathrm{p} \leq .01)$ and rational/cognitive coping $(\beta=-.17, p \leq .01) . R^{2}$ was $42.3 \%$ in the final model explaining variance of anxiety.

Significant predictors of depression were female gender $(\beta=.26, p \leq .001)$, higher insufficiency $(\beta=.11, p \leq .05)$, ambiguity $(\beta=.13, p \leq .05)$, and lower levels of recreation $(\beta=-.19, p \leq .001)$, social support $(\beta=-.19, \mathrm{p} \leq .001)$ and rational/cognitive coping $(\beta=-.24, \mathrm{p} \leq .001) . \mathrm{R}^{2}$ was $48.7 \%$ in the final model explaining variance of depression.

\section{Figure 1. Explained variance of anxiety and depression.}

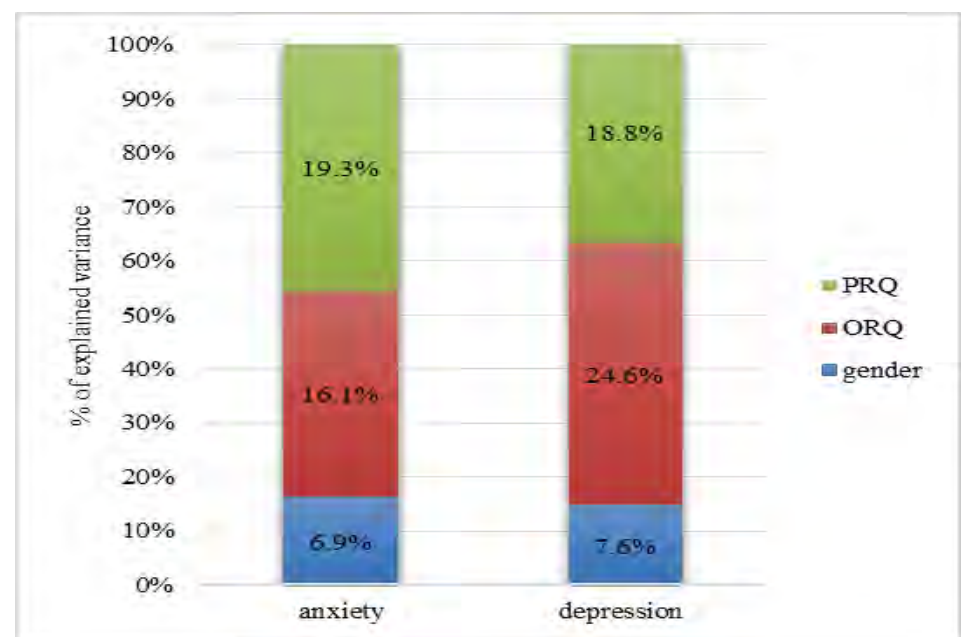

Notes: ORQ=Occupational Role Questionnaire (role overload, role insufficiency, role ambiguity, role boundary, responsibility, physical environment); $\mathrm{PRQ}=$ Personal Resources Questionnaire (recreation, self-care, social support, rational/cognitive coping) 
Figure 2. Multiple regression analysis: gender, occupational roles and personal resources on anxiety.

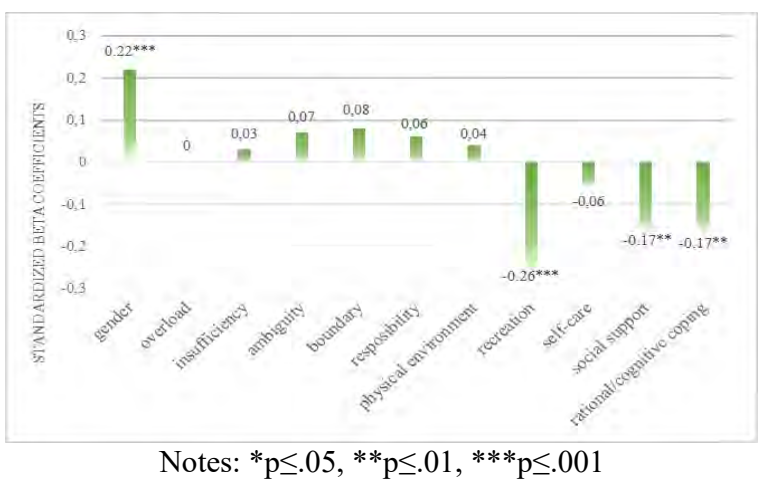

Figure 3. Multiple regression analysis: gender, occupational roles and personal resources on depression.

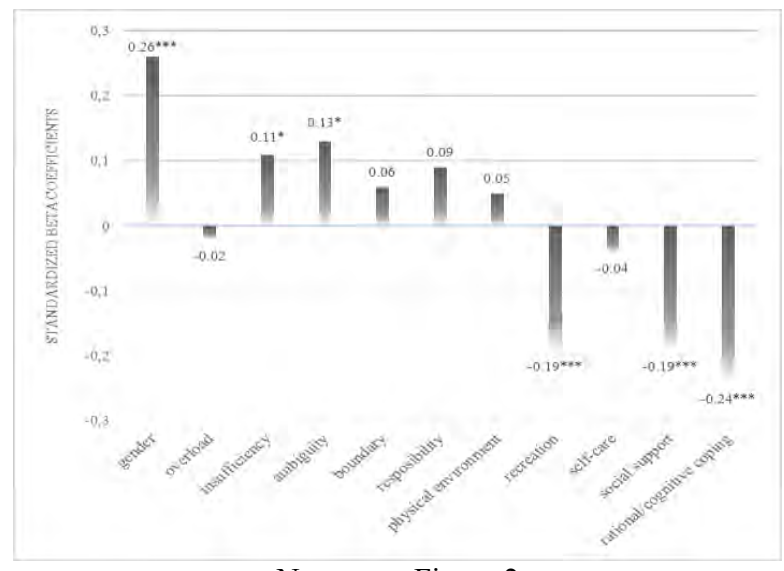

Notes: see Figure 2

\section{Conclusions and practice implications}

Results revealed that female gender was risk factor for anxiety and depression. Role insufficiency and role ambiguity were risk factors for depression. The outcomes support the importance of personal resources in reducing of anxiety and depression. Higher levels of recreation, better social support and good rational/cognitive coping strategies in the work of high risk employees were significant predictors for decreasing of perceived anxiety and depression.

This study may predict similar findings in other high risk professions that are predominantly male ones, such as soldiers, rescue workers, firefighters, dispatchers and others. The examined groups were specific and closed, therefore obtaining of their responses was difficult.

There is a paucity of interventions that target psychosocial work factors in high risk professions. Therefore, design of effective interventions to promote employees' psychological well-being is very important. Since Slovakia does not have any specific regulations on work-related stress, another general legal framework should refer to psychosocial risk factors that may enhance work-related stress.

\section{References}

Baumann, A., Muijen, M., Gaebel, W. (2010). Mental health and well-being at the workplace-protection and inclusion in challenging times. Copenhagen: The Regional Office for Europe of the World Health Organization.

Bennett, P. (2011). Abnormal and Clinical Psychology. Berkshire: Open University Press.

Madsen, I.E., Nyberg, S.T., Hanson, L.M., et al. (2017). Job strain as a risk factor for clinical depression: systematic review and meta-analysis with additional individual participant data. Psychological Medicine, 8, 1342-1356.

Národné centrum zdravotníckych informácií NCZI. (2018). Psychiatrická starostlivost' v SR 2017 Bratislava: NCZI.

Schneider, A., Weigl, M. (2018). Associations between psychosocial work factors and provider mental well-being in emergency departments: A systematic review. PLoS ONE 13, Nov. 29, 2019: https://doi.org/10.1371/journal.pone.0197375. 